\title{
A focus on the burdens, boosters, and bonuses of the bearers of bad news in India
}

\author{
Lawrence Martis', Anne Westhues ${ }^{2}$ \\ ${ }^{1}$ Social Aetiology of Mental Illness, Centre for Addiction and Mental Health, Canada \\ ${ }^{2}$ Anne Westhues, Faculty of Social Work, Wilfrid Laurier University, Canada
}

Correspondence: Lawrence Martis, Social Aetiology of Mental Illness, Centre for Addiction and Mental Health, Canada. Email: lawrence.martis@utoronto.ca

\begin{abstract}
Objectives: This study was done to explore the experiences of physicians in India about being the messengers of bad news and management of psychosocial burdens associated with such consultations.
\end{abstract}

Methods: Narrative data was collected from 27 physicians working in four teaching hospitals, using a semi-structured interview schedule. Constant comparison analytic procedures were used to examine physicians' perceptions and behaviors related to their role as the bearers of bad news. Results: Physicians perceived that being a messenger of bad news was very challenging throughout the course of their careers, although their self-confidence increased over time. Two types of patient care contexts were identified based on the intensity and duration of distress experienced by the physicians. Treatment failure with children and young adults, patients' inability to access care at the initial stages of the disease, and withdrawal of life-saving treatments due to financial constrains caused intense distress among physicians. Physicians used a number of strategies to cope with the burden of bearing bad news. Clinical bad news puts physicians at risk for burnout, and in some cases is an opportunity for growth.

Conclusions: Clinical skill trainings should increase clinicians' ability to assess and attend to the psychosocial impacts of delivering bad news as much as teaching them the procedures of conveying such information. More studies about the impacts of bad news disclosure on physicians working in societies or settings with inequitable access to health care will improve such training programs.

Keywords: Physicians in India, breaking bad news, truth telling, self-care among physicians, medical education.

\section{Introduction}

Among clinical interactions, truth or bad news disclosure is most challenging for clinicians because it questions their role as healers. People usually expect good news and physicians would love to confirm that all is well or can be made well, but may have to give bad news even before they have had time to form a trusting relationship with them. ${ }^{1}$ When physicians cannot offer any viable alternatives to modify the disease trajectory, they find it hard to deliver such information to patients and families. For example, 167 oncologists practicing in various countries informed Baile and colleagues $^{2}$ that telling patients about relapsed cancer, treatment failure, the end to curative options, and hospice referrals were more difficult than providing the initial diagnosis. Bad news disclosure is hard because it contradicts clinicians' identity as assuagers of distress and demands of them skills to support emotional patients and families. Research has identified a variety of psychological reactions of the recipients of bad news that include shock, sadness, fear about functional impairments, a diminished sense of control, loss of hope, and death anxiety., ${ }^{3,4}$ Based on the responses of 500 health care professionals gathered for a symposium in the USA, Baile, et al. ${ }^{5}$ highlighted the contradictory nature of clinical communication in the context of bad news. They reported that $58 \%$ of the participants rated bad news disclosure as very challenging because it involved providing honest medical truth and preserving hope among the recipients of such news, at the same time. In bad news situations clinicians face more questions from patients and 
families than in other clinical care contexts. ${ }^{6}$ However, estimating survival, level of functionality, and treatment outcomes is never easy. ${ }^{7}$ Clinicians have to convey information to patients and families whose capacity to absorb and retain information is compromised by distress. ${ }^{8}$ Making decisions about the amount and timing of bad news disclosure to patients, ${ }^{5}$ and identifying potential misunderstandings about prognosis and treatment goals ${ }^{9}$ make bad news interactions burdensome for clinicians. In short, bad news consultations test the competence of physicians unlike any other communicative task because such situations impose on them the dual responsibility of transmitting unfavourable health information effectively and managing the emotions of those who receive it.

Bad news disclosure is hard for clinicians not only because it hurts patients and families but it also adversely affects their own lives in various ways. Researchers have reported a significant increase in biophysical responses such as cardiovascular reactivity and psychological stress among clinicians who participated in simulated bad news consultations compared with those who delivered good news or were engaged in nonclinical tasks such as reading or watching television. ${ }^{10-12} \mathrm{~A}$ qualitative study by Friedrichsen and Milberg ${ }^{13}$ described the complex psychosocial stress experienced by 30 Swedish oncologists who experienced loss of control in almost all aspects of their life. They found it hard to control their emotions, thoughts about their own mortality, doubts about their professional skills, feelings of helplessness, and loneliness. Similarly, Canadian medical interns who participated in a focus group study on truth telling reported prolonged anxiety about dealing with the emotional reactions of their patients and families. ${ }^{14}$ A study by Ptacek and colleagues ${ }^{15}$ highlighted the intensity of psychological disturbance suffered by the messengers of bad news. They asked 38 physicians in the US to recall a recent bad news consultation and comment on its impact on them. All reported that the transaction was stressful but $86 \%$ of them said it was moderately stressful, meaning that the stress lasted beyond the interactional encounter. The stress associated with truth telling lasted between a day and three days for $42 \%$ of the participants. To sum up, the studies discussed above indicate that bad news adversely affects various aspects of the messengers of such information in a profound and prolonged manner.

As clinical bad news adversely impacts those who convey and receive it, bad news disclosure should be considered a core competency in medical education. Research has shown that such consultations are primarily handled by physicians, even though allied health care professionals share the burden of breaking bad news. ${ }^{16-18}$ Clinicians talk to people more often than they perform any other medical task, but very few receive any formal training in communication skills. ${ }^{19}$ More years of clinical practice do not necessarily mean that they get better at assessing and attending to their own emotional needs. ${ }^{1}$ Clinicians require training to manage bad news recipients' emotions, their own sense of failure to save lives, sorrow at the death of their patients, anxiety about being blamed and not having answers to bad news recipients' questions, and to overcome the thoughts of their own death or disability. ${ }^{1,13}$

Research has shown that deficient training in clinical communication is a risk factor for mental illness and morbidity among clinicians. For example, 28\% of the 393 British oncologists and palliative care specialists surveyed by Ramirez, et al. ${ }^{20}$ were found to have a psychiatric disorder. Approximately $1 / 3$ of them reported high levels of emotional exhaustion and a sense of low personal accomplishment, two elements that contributed to burnout. Importantly, clinicians who felt that they were insufficiently trained for tasks related to information transmission and management of emotions reported higher levels of distress than those who perceived themselves as sufficiently trained to handle such communicative responsibilities. Similarly, Brown ${ }^{11}$ observed 12 medical interns and 12 expert clinicians in the context of a simulated bad news consultation and found that inexperienced clinicians recorded higher levels of depression, stress, anxiety, and fatigue, which compromised the quality of bad news consultation. Lipton ${ }^{21}$ pointed out that communicative incompetence is not only harmful to individual clinicians but also to health care systems because it contributes to suboptimal patient care and loss of highly trained health care professionals due to burnout. To conclude, all clinicians should receive quality clinical skill training related to bad news disclosure to be able to recognize the impacts of such interactions on their lives, to cope with stress, and thereby to provide optimal care to patients and families.

Quality and comprehensive clinical skill training presupposes empirical knowledge about the intricate processes of truth disclosure in various sociocultural contexts across the globe. It is important to incorporate the experiences of physicians into training who are working in low and middle income countries such as India, where little is known about the hardships faced by them in the context of clinical bad news and their efforts to cope with the bio-psychosocial impacts of such difficult consultations. Although considered to be a powerhouse of the global economy, India is still a country of plentiful clinical bad news because it is among the top 10 countires in the world with the highest rate of disease incidence and mortality.2 Indian researchers have focused on palliative care, patient autonomy, and informed consent rather than physicians' experiences related to delivering bad news. Some studies have emphasized the need for well-trained physicians to break bad news. For example, Bharadwaj and colleagues ${ }^{23}$ reported that only $15 \%$ of the 111 medical residents who participated in their study felt that they had been adequately trained to deliver bad news. A focus group study by Supe ${ }^{24}$ identified several institutional barriers encountered by 12 medical interns 
when breaking bad news in two hospitals in Mumbai. In another study, 21 of the 35 radiation oncologists said that they felt depressed after communicating bad news to patients and families. ${ }^{25}$ However, this study focused on the attitudes of radiation oncologists about delivering bad news rather than its implications for their lives and the ways and means of managing their stress. The extant literature leaves many questions unanswered such as: 1) What are the perceptions of physicians in India about the psychosocial outcomes of truth telling on their lives? 2) What makes a truth telling situation more or less stressful? and 3) How do physicians manage the stress of being the messengers of bad news? We wanted to generate a theoretical framework on truth telling to guide clinicians and to educate medical students in India and abroad about the most challenging type of clinical communication. So we designed a study to explore the experiences, attitudes, and behaviors of physicians in India about delivering bad news to patients and families in the context of life-limiting, progressive, and advanced diseases.

\section{Methods}

\section{Research design}

A qualitative research design seemed most appropriate to answer the above questions because the purpose of our study was to explore and understand rather than quantify the subjective world of the messengers of bad news. A qualitative approach to research offers in-depth accounts of a social phenomenon by focusing on the world of meanings created by the participants, always recognizing that the perceptions are multiple, complex, and irreducible to a few hypotheses. ${ }^{26}$ Among a range of qualitative approaches to empirical enquiry, we chose the grounded theory method developed by Glaser and Strauss ${ }^{27}$ because it facilitates generation of new theories by inductively creating concepts from people's experiences and meaning-making processes. Grounded theory methodology has evolved into many forms based on the epistemological and ontological perspectives of researchers that range from realism to relativism. ${ }^{28}$ Glaser and Strauss, the originators of the grounded theory method, did not subscribe to any particular ontological view, however, we believe that their guidelines correspond with critical realist-constructivist ontology, which allows researchers to integrate both objectivist and constructivist grounded theory variants. According to Healy and Perry, ${ }^{29}$ a critical realist-constructivist lens allows researchers to explore the multiple meanings constructed by people about a single and relatively mind-independent reality. This ontological standpoint helped us to construct concepts and categories by prioritizing physicians' perceived psychosocial impacts of delivering bad news and the strategies they used for managing their stress. In other words, we tried to suspend our pre-conceived ideas or extant theories on truth telling to understand our partici- pants' meanings, but also recognized that the emergent conceptual framework is only a constructed product rather than an absolute representation of the studied reality. ${ }^{30}$

\section{Sample}

We recruited the participants for this study at four teaching hospitals, three in Bangalore and one in Mangalore, which are the prominent cities of Karnataka province in India. A letter of invitation was circulated to physicians, asking them to contact the first author if they had at least two years of post-MBBS (Medical Bachelor and Bachelor of Surgery) clinical experience and were willing to share their experiences about breaking bad news to patients and families. A consent form was sent to 41 physicians who showed interest in the study but only 27 were interviewed because the simultaneous data and concept generation procedure, a fundamental element of grounded theory method, suggested that the categories had reached saturation.

Initially, a purposive sampling procedure was used to generate data with maximum variation of views and experiences concerning truth telling by including physicians from a number of medical specialties, both male and female, ranging in age from 28 to 63 years. Their medical specialties are summarized in Table 1 . On average, they had 18 years of medical practice after completing the MBBS and all of them had earned post graduate degrees. Six participants had completed specialized training programs overseas for a year or more. Another three participants had worked in foreign countries for more than 4 years.

Table 1. Demographic characteristics

\begin{tabular}{|c|c|}
\hline Characteristics & $\mathrm{n}$ \\
\hline \multicolumn{2}{|l|}{ Medical specialty of participants } \\
\hline Cardiology/Chest medicine & 3 \\
\hline General medicine & 5 \\
\hline General surgery & 3 \\
\hline Gynecology/OBG & 3 \\
\hline Nephrology & 2 \\
\hline Oncology & 6 \\
\hline Paediatrics & 3 \\
\hline Pain \& palliative care & 2 \\
\hline \multicolumn{2}{|l|}{ Sex } \\
\hline Male & 19 \\
\hline Female & 8 \\
\hline \multicolumn{2}{|l|}{ Age } \\
\hline Average & 42 years \\
\hline Range & $28-63$ years \\
\hline \multicolumn{2}{|l|}{ Years of post-MBBS medical practice } \\
\hline Average & 18 years \\
\hline Range & $5-33$ years \\
\hline \multicolumn{2}{|l|}{ Number of bad news events handled in a week } \\
\hline $1-10$ events & 15 participants \\
\hline $11-20$ events & 12 participants \\
\hline \multicolumn{2}{|l|}{ Completed a course/training on clinical communication } \\
\hline Yes & 11 participants \\
\hline No & 16 participants \\
\hline \multicolumn{2}{|l|}{ Types of hospital experience } \\
\hline Worked only in public hospitals & 6 \\
\hline Worked only in not-for-profit hospitals & 7 \\
\hline Worked only in corporate hospital & 1 \\
\hline Worked in two or all three types of hospitals & 13 \\
\hline
\end{tabular}

Subsequently, we employed theoretical sampling procedures to saturate the emerging categories. For example, the data analysis indicated that the impacts of delivering bad 
news may differ considerably across public, not-for-profit, and corporate (for profit) hospitals. So we asked the participants to share their experiences at different hospitals rather than limiting them to their current not-for-profit setting and we also expanded the study sites to include physicians currently working in public and corporate hospitals.

\section{Data collection}

All of the participants provided us with the demographic information noted above. We also used field note forms to record the observations and ideas that emerged during the planned interviews with the participants, and in unplanned encounters with other health care professionals, patients, researchers and administrators. A substantial amount of data was generated through one hour semi-structured interviews with each of the 27 participants. We interviewed eight participants for a second time for about 15 minutes to obtain clarifications and additional information. The first author conducted all of the interviews in English, and transcribed verbatim from the digital sound recordings, anonymized to ensure the privacy of participants. Another member of the research team reviewed the transcripts and gave suggestions for next interviews.

\section{Data analysis}

We analyzed narrative data by following the two-level iterative procedure suggested by Glaser ${ }^{30}$ with the aid of NVivo (version 9). The first level of analysis involved open coding procedures which generated five conceptual categories. This was followed by selective coding which helped to identify "creating communicative competence" as the core category. During the open coding phase we made a conscious effort to be open to all theoretical possibilities when labeling actions and interactions in the data as concepts. Selective coding involved choosing a category that explained most of the perceptions, actions, and interactions in the data. During the second level of analysis, we employed the theoretical coding tools suggested by Glaser ${ }^{31}$ to assemble the conceptual categories into a theoretical structure by connecting categories with each other and with their properties.

We also used a number of procedures to ensure the quality of the emergent theory. For example, three experienced researchers independently reviewed the codes and checked the correspondence between the pieces of raw data coded under each category and its properties. As a memberchecking technique, approximately 150 professionals belonging to various health care disciplines at two participating hospitals provided feedback on the emergent theoretical framework during one hour clinical forums. The multiple data sources - demographic, observational, and narrative - plus immersion for one year at the study sites has contributed to the quality of data and the study in general.

\section{Ethics review}

Prior to data gathering, the Research Ethics Boards at Wilfrid Laurier University in Canada and St. John's National Academy of Health Sciences in India approved this study. We provided potential participants with all of the information necessary to make an informed decision about participating in the study, and documented their consent. All of the participants willingly permitted us to use their quotes in the research products after identifying information was purged, and offered to meet again to provide any clarifications.

\section{Results}

Analysis of the data revealed two inseparable aspects of truth telling. One was the cognitive-behavioral processes of transmitting the medical truth to patients and families, which we coded as "Diligent Disclosure". A second denoted the affective processes involved in managing the psychosocial outcomes of bad news, which was coded "Caring Disclosure". Caring Disclosure yielded two subcategories; one focused on bad news recipients' need for emotional and psychosocial support and the other highlighted the impacts of bad news interactions on physicians, the messengers of bad news. Here we present the findings related to the second subcategory because it answers the questions relevant to this paper.

We will explain four concepts related to the impacts of bad news on clinicians: 1) Bearers' Burdens captures physicians' meanings of bad news and the intensity of psychological stress they experienced in different patient care contexts; 2) Burned out Bearers highlights the adverse outcomes or at-risk situations of bad news deliverers; 3 ) Bearers' Boosters identifies some of the psychological mechanisms and social supports that helped clinicians to cope with their stress; and 4) Bearers' Bonuses documents the perceived personal growth amidst bad news situations. We have illustrated the categories and subcategories mentioned above in Figure 1 to give an overview of our findings on the impacts of bad news on clinicians in India.

\section{Bad news bearers' burdens}

The concept "Bearers' Burdens" presents physicians' conceptions about what constitutes bad news. It also captures the intensity of the psychological stress they experienced in different patient care contexts and the impacts of bad news consultations on various aspects of their lives. For example, one medical oncologist said:

"I think it [providing bad news] has effect on every part of our life."

\section{Meaning of bad news}

Analysis of the data revealed that physicians conceptualized clinical bad news not so much by the disease type, such as cancer, but by the patient care contexts in which they could do little to modify the outcomes of clinical satiation. 


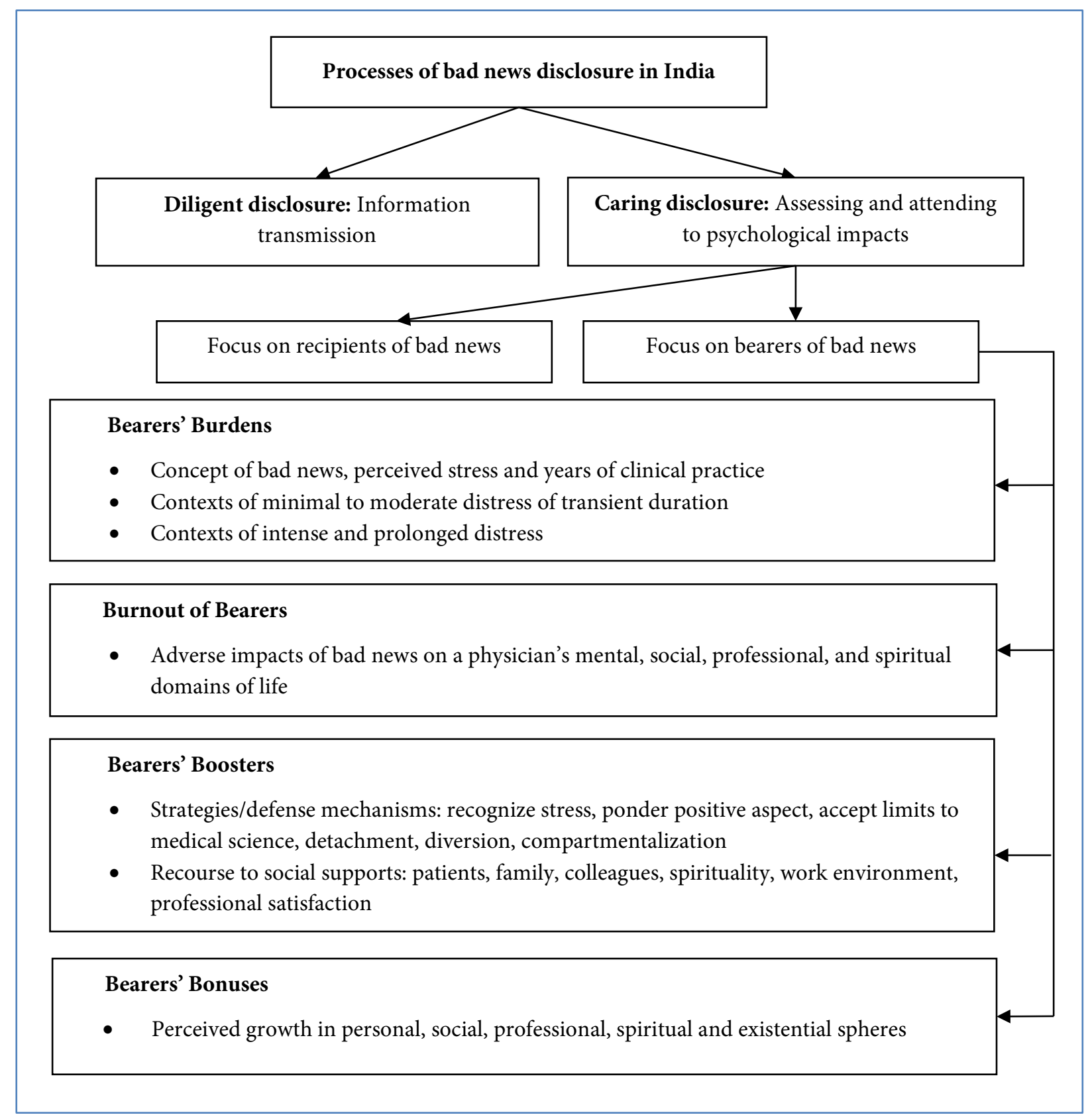

Figure 1. A focus on the bearers of bad news in India

Importantly, the clinical situations they described were not necessarily related to an unsolvable medical issue but were related to the socioeconomic background of patients. For example, physicians narrated situations that forced them to withdraw promising interventions because patients could not afford them. A male oncologist expressing frustration about being prevented from providing care for economic reasons said: "It is bad news for us". Whether the bad news was directly related to a biomedical issue or a socioeconomic one, physicians perceived all such encounters as burdensome for them, as the following quote by a female physician practicing general medicine suggests:

"Yes. Definitely, it is not a good experience. I do not think any-

body enjoys giving bad news, but in situations, breaking bad 130 news about the diagnosis where there is treatment or cure, I do not feel very bad. The situation is one which I can sit and talk to most of the patients. I am more confident in doing that. We just assure them that there is a treatment for this and we are going to help you out. When it comes to life-limiting, particularly endstage, we feel really helpless that we are not able to do anything."

\section{Breaking bad news never easy}

Many participants suggested that more years of clinical practice provided them with opportunities to test and solidify their communicative skills. A physician may not have successfully conveyed bad news in every instance, but learned from his or her mistakes, as the following quote suggests: 
"Definitely, I feel, over the years, if you are sensitive, your competence will grow because over the years, you will pick up many things. You see then how they react and how you can break it in a smooth way. It will be, basically, if you see them having more emotional breakdown, the next time you will be more conscious. You will make [an] effort not to break bad news in that way and modify it in a manner that they will not have [an] emotional breakdown. Slowly, by practice, you will learn."

However, the analysis of their seemingly contradictory narratives revealed that perceived confidence about one's capacity to communicate bad news can coexist with feelings of clumsiness or being challenged by this task. We found that many physicians who reported that they were capable of communicating bad news fairly well, in another part of their narrative, expressed doubts about their ability. For example, one physician said:

"I didn't have major problems in communicating with families... But all said and done, even now it is difficult to convey bad news and especially to communicate about imminent death.”

Another female gynecologist said:

"Whatever may be, how many years we practice, telling bad news to different patients is, you know, is like the first only. Each patient is different and you cannot think that I have told bad news to so many. Each is a new patient. If somebody comes and tells that I have had experience of so many years, and just comes and tells without any feeling, I don't know how that patient and patient party also will feel."

Another male general surgeon with 22 years of clinical practice suggested that bad news consultations are always challenging for him:

\begin{abstract}
"There is no situation, where I felt it is easy to communicate to the patients; there is always strong emotional element either with the patient party [family of patients] or with me. I never felt easy or happy doing it [breaking bad news]. I really can't say something was very easy to communicate; it is not easy."
\end{abstract}

In conclusion, participants in the study perceived patient care contexts that questioned their role as healers as bad news either because they had no interventions to modify the disease, or patients could not afford treatments that were available. They always found it burdensome to transmit bad news to patients and families, even though greater exposure to bad news over the years gave them more confidence to face these encounters.

\section{Two kinds of burdensome interactions}

Analysis of the data revealed that the level and duration of perceived burden varied depending on the disease type, age, social role of patients, personal make-up of a physician, and the intensity of the clinical relationship. For example, one clinician in the department of general medicine highlighted the strength of the patient-physician bond as a factor that contributed to his sense of burden when breaking bad news:

"If you are involved with your patients for a long time, we do become emotional because if the patients are very much at- tached to us, long term patients, we do become emotional...It depends on the association with the patient, whether it is your relative, friend, or otherwise. You know, your association with the patient makes the difference."

We analyzed reports of bad news interactions by focusing on the degree (intensity) and duration (temporality) of psychological stress experienced by physicians and classified them as 1) minimal to moderate level of stress of transient nature or 2) intense and lingering stress. A minimal to moderate level of emotional disturbance lasted up to a day, and was of a transient nature. In the second category, the stress was so intense that the physicians took it home and struggled with it for more than a day, sometimes even for weeks. The following quotes illustrate the difference between these two types of experiences:

\begin{abstract}
"It does not stay there for long. Once you have actually transferred [news about] this loss from yourself to somebody else, it ends there. Then you don't feel so much; once you have spoken to the relatives and made them understand that there has been a death. Actually, you stop thinking about it."
\end{abstract}

"Like an ostrich, I would hide at home. Once I am free [of hospital duty], I do not talk, do not go for socializing. And this not one or two days; it will go on 'til the next situation goes well."

Physicians' reported stress ranging from minimal to moderate levels in situations when bad news was expected by patients and families. Specifically, if patients were brought to the hospital in a serious condition, were in treatment for a long time, suffered multiple complications, or were surviving on life support, the perceived psychological impact was relatively less for physicians. These situations made physicians think that "the inevitable is happening... What you can do? The disease has run its course". There were exceptions to this statement however. If a physician had developed a stronger bond with the patient either in the patient care context or outside of it, then they found it very burdensome to communicate bad news and the stress lingered.

The contexts that contributed to intense and lingering stress for physicians included situations when the health condition deteriorated unexpectedly or caused untimely death. Many physicians noted that bad news regarding children was the most disturbing for them because of the tender feelings people tend to have towards children, who "suffer so much". Some physicians were also concerned about the side effects of the treatment on children, and the difficulty of dealing with emotional parents, particularly if the patient was the only child to the parents. Some physicians could see the face of their own children or grandchildren in the ill child, and therefore the bad news interactions were more burdensome for them:

\footnotetext{
"The child's malignancy affects the doctor most. It disturbs us very much. Probably we have children at home in the same age group. Compared to adult malignancy, the children's malignancy requires more emotional stability in doctors. Because the child is quite innocent and basically we presume and feel that
} 
we do not know what is the consequence of treatment, the side effects of treatment and so many things he has to face at [a] very young age; whereas in adults, although there are issues, probably it is a little bit different, or less emotionally disturbing for the doctor."

Similarly, physicians found it hard to handle bad news about adults with parenting responsibilities, who were the primary providers for the family, or who had greater responsibilities compared to older patients. A permanently and profoundly debilitating disease or the death of persons with family responsibilities induced intense pain for physicians, as this quote suggests:

"I probably felt more for people when you see they have so much responsibility left behind and there are some patients who really come out and tell [the]whole thing. Say, I have a son, I want him to do well. It does affect a great deal, a great deal (distressed voice)."

Some physicians identified with the patient and perceived in such patients his or her own physical frailty and mortality. For example, a gynecologist spoke about her prolonged grief over the death of a young mother who died due to postpartum hemorrhage:

"She was like [a] daughter to me."

Another physician said:

"When death happens, I feel that it is my own loss and you tend to carry it home."

And yet another said:

"Sometimes it keeps coming again; especially I really get distressed if the patient is of my age with children and with a husband. So, I identify myself with them, you know. That really disturbs me."

Situations involving "sudden bad news" or the unexpected deterioration and death of a patient hospitalized for a treatable or manageable disease challenged the physicians most and they felt helpless to explain the situation. They found it very hard to interact with the family in these cases, and were embarrassed by the inability to diagnose the disease or to identify the cause of deterioration, as illustrated in this quote:

\footnotetext{
"Sometimes there are deaths which you cannot explain and it troubles you why it happened and you do not know the answer why it happened. Those things will linger on for some time because you are still searching for an answer for what went wrong...If you do not know why there was death. And then what really bothers is that it could happen again."
}

Providing information about failed interventions and poor medical decisions was another area that caused high levels of stress among physicians:

"Very rarely, there are times when, if I have not done [a treatment] correctly, I suppose I feel, you know, may be if I had done it in a different way, the child might have been saved. Those are the conditions where even at home I would be thinking about it. Throughout the night I would be thinking about it and I do not get sleep. So, if you have [the] feeling that you have not done it right, if you could have changed the outcome by doing it in a different way, then the guilt feeling continues."

Dealing with death was very disturbing to some physicians because they believed that saving life is the goal of their profession. They revealed that their communication skills and ways of supporting people were challenged most when they were with the grieving and traumatized families. A cardiologist compared his comfort level in communicating with a patient with a manageable disease and speaking to a grieving family:

\begin{abstract}
"Most of the time we tend to spend [a] couple of minutes more with the patient and tell them 'see, we will try to look further into it'. Whereas the situation gets even worse when the patient dies when you are standing there and [the] patient-party is breaking down. That's the time I guess no matter what you talk, [it] does not matter to anyone because you know that you've lost your beloved. You would want that person [to] live more."
\end{abstract}

Almost all of the physicians expressed their anguish about having to communicate bad news to patients who could not access care in a timely fashion when the disease was treatable. They narrated many instances about patients forced to withdraw from treatment prematurely for financial reasons. Physicians could not digest such scenarios and felt "blocked" in their professional duty. One participant commented that "it is bad news for us" and another said that the financial problems of the patient are "an added botheration" for the physicians. In situations where patients and family caregivers invested their meager savings, sold the land or equipment on which they lived, or had to make hard choices between providing treatment for the ill child and depriving their other children, physicians experienced immense pressure to produce better outcomes. They felt obliged to manage the health condition and save the life because the patients had invested so much in health care. The following quotation, by a female nephrologist captures these dynamics:

\footnotetext{
"But when it comes to 18 or 20 year old children, it becomes very hard... Are they bankrupting themselves? Who else is going to suffer as a result of this? Is the whole family going to be in the debt ring for the next 10 to15 years? Am I doing the right thing? So, that's the big conflict we face. It doesn't deal with bad news but it is one of the factors that cause conflict and stress in your mind...So, that's another stress one has to deal with and that is very (emphasis) hard stress."
}

Physicians recounted their feelings of helplessness, regret for advising costly treatments that could not save the life, feelings of depression, the burden of planning treatment by weighing the costs and benefits rather than patient's need for care, feelings of guilt, a sense of being inhuman, and even feeling unprofessional:

\footnotetext{
"Of course, that [a patient terminating treatment for financial reasons] is definitely a bad news for us, because we always feel guilty about it. We carry that guilt; like, I could not do because
} 
of money. It is not that I am blaming anybody for that. Might be, we all are constrained, financially constrained. But as a human being, we should have saved him and money is not important. That is what we are taught. We are not doing it. We are cruel in some ways. Some ways we are contributing."

In sum, physicians expressed experiencing greater distress when they could not explain and address deterioration in the health status of patients, and when treatments given to children and adults with unfinished family responsibilities failed. It was a unique stressor for physicians when treatments were withdrawn prematurely for financial reasons.

\section{Burned-out bearers of bad news}

Analysis of the data suggested that being a messenger of bad news was not like couriering information in a sealed envelope, carefree of its contents and consequences to the recipients. Physicians indicated that the impact of continuously delivering bad news was not restricted to the professional sphere of their lives but pervaded the psychological, social, and spiritual domains as well, as is evident in the following quotes:

"I think it has effects on every parts of our life."

And,

"Yes, [my distress] prolongs to quite some time and sometimes, spills on to other work also. When we go and see something else, will be like, not really concentrating on that or any other work. We still keep thinking about these people crying in our office or OPD [Out Patient Department]."

Sometimes, the accumulated psychological stress became so pronounced that they experienced and exhibited an altered personality as narrated by a male oncologist:

"Unfortunately, a happy person might become a sad person, being temperamental with students and children at home or may just stop communicating bad news... The stress of it affects most part of my social life. I go back home depressed; that is exactly what my wife does not want when I reach home. She doesn't want me to come with sorrow face, sad face, and no happiness and we have had a lot of problems because of that... So definitely, it has changed my personality because I don't remember anybody having commented upon something like that about my personality saying that you are a sad person."

A gynecologist talked about the negative implications on her spiritual life and said that:

"You may turn away from God also. You may turn away from your spirituality.”

It is important to note that participants reported that the stress associated with being a messenger of bad news adversely affected their communicative capacity and contributed to professional burnout as implied in the words of a general surgeon:

"I have seen so many people who stop it at that. The fear factor aggravates and once you have that fear factor, it is very difficult to get back to work and communicate with the patient or family. I have seen some people who just cannot take it and they cannot break it [bad news] any further. There are extremes that they stop operating. They do not want to take it anymore because I have seen really big ones [who could not] handle the pressure. It is [a] lot of pressure."

\section{Bad news bearers' boosters}

Physicians discussed their self-care strategies and identified the social supports that helped them to handle the stress of being a messenger of bad news, thereby helping them to support patients and families as one male nephrologist put it: "I have learnt to get over it [stress]". These strategies and supports were grouped under "Bearers' Boosters".

\section{Recognizing the stress}

Some participants suggested that the first step in overcoming stress is acknowledging truth telling as a hard task and that being upset is natural. In this regard one participant said:

"I think, many times, when I am talking to the families, I am upset. Sometimes, I feel like crying but I think I control it because men are taught not to cry (laughs). So, I understand what they are going through. So, I think, it is natural for me to be upset, but I make a conscious effort to make sure that my reactions or emotions do not come in the way of patient management. That is one thing that I definitely try to do my best."

\section{Pondering the positive side}

Many participants revealed that they first communicate the positive aspects of the disease process, medical reports with favorable information, and success achieved in managing symptoms and only then convey bad news to patients and families. Similarly, they pondered on their efforts and past successes in reducing the impact of bad news on patients and families, as a way of coping with the stress emerging from the current patient care situation. This strategy is illustrated by the following quote:

"Seeing each bad incident as part of the profession and not as
the last case; pondering the positive side of a bad event, success-
ful cases, and the determination to move on helps in coping."

\section{Accepting the limits of medical treatment}

Recognizing that medical science has its limits and a physician cannot cure all diseases was another strategy for coping. This perspective helped physicians to accept a failure to cure or save life and to overcome guilt:

"Once I realized that I was not wrong, one consolation was there... you have done your best. You are not God but this I keep telling every time to myself. I am not God but what best a human being or a doctor can do, as a specialist can do, I have done. It gives me a sense of satisfaction, though the failure has happened."

Some physicians tried to overcome the remorse associated with denying treatments because of financial constraints by rationalizing that death is universal and an inevitable aspect of life and he or she had done all that could be done. Rationalization, which is a common psychological process of 
coping with stress, was evident in the narratives of many participants. For example, one male oncologist said:

"...but then I invoke the regular doctor defense mechanism, which is disassociating ourselves from that situation. We just say, 'oh, this patient died. What can you do, he had cancer'."

\section{Detachment}

Some of the participants suppressed the feelings associated with bad experiences and decided to forget the bad event. For example, a clinician specialized in internal medicine said:

"So, I think, that's the defense mechanism that you put away certain things from your mind because you know that certain things make you feel bad and therefore you do not want to recall them."

Some others avoided emotional attachment to patients, as one said:

"The other thing what I do is, when I know that I am getting attached to a patient--because you are dealing with emotional issues--I do not want to see that patient going away to die."

\section{Diversion}

A number of participants reported that taking a break from usual clinical tasks for a day or two, engaging in entrainment activities, reading, and doing some less stressful clinical work helped them to overcome the distress that emerged from bad news consultations. This strategy is illustrated in the words of a female nephrologist:

\begin{abstract}
"In the] initial, half an hour, I was unable to concentrate on other work, other patient care. I sat in my chamber for some time, and then I did some paper work and clerical work which was pending there to do. I finished off that; had a cup of coffee, refreshed my mind, and I started my rounds. If I had gone immediately to the next patient, all my reflection would have been different. So, I thought that I should take some time off for myself and get this thing out of me and then go for routine rounds."
\end{abstract}

\section{Compartmentalization}

Several participants described putting a boundary between professional and other aspects of their life as a way to contain stress. One pediatric nephrologist put it this way: "We insulate, I mean, we compartmentalize". A female palliative medicine specialist said:

"Usually, I have all these feelings when I am in the hospital and I may be thinking about it on the way home. Once I reach home, I have a different set-up, duties and responsibilities. So there I forget this whole thing and I am involved in the other kind of work."

\section{Spirituality}

A number of participants belonging to various religious or spiritual systems narrated that they find their spiritual beliefs and rituals help to deal with stress associated with patient care and clinical communication. The following are some examples:

"Do our best and after that it's in God's hand; can't do much about it."

And,

"For my own satisfaction, I do lot of Pooja (worship) and Yoga and I will overcome all that hum."

"Ultimately, everybody will have to die; so that's the way it is. We cannot do anything. It's all in God's hands. Beyond a certain stage, we do not have any power in our hand. We cannot do anything. Everything is God's wish."

\section{Patients and families}

Participants suggested that in the clinic a physician encounters a group of unusual, nevertheless very informative and resourceful teachers - the patients and family caregivers:

"They are the teachers of my life; patients are my teachers. I am learning from them". "Generally, people who are concerned with the disease always help us to cope with it."

\section{Family and colleagues}

Several participants noted that talking with family members or colleagues can be helpful in dealing with the stress of breaking bad news. The following are two examples:

\footnotetext{
"I would tell first factor is spirituality and next factor is interpersonal relationships. You come and talk about whatever problem you have, any bad news you have to break, with your colleagues and somebody will ease your mind out. So, that will help you; either your family members or your colleagues, usually colleagues. Somebody else also had similar problems, this happens. So then you feel little easier."

"We have an extremely good department; the support system in the medical department is very cohesive; so I tell my colleagues and they tell me about similar incidents; it helps to talk, to ventilate; that's the big thing."
}

\section{Work environment}

Job satisfaction, devotion to duty, and a satisfying work environment helped in managing the stress of being a bearer of bad news, as this participant explained:

\footnotetext{
"And much more than that, we work in an environment as (name of the study site). The management is very supportive of what we do and we tend to do work in a set up where we do provide care for very underserved population. That is very satisfying. All those things help in dealing with the stress. If you are happy with your work, I think the stress is very minimal; does not become so hard."
}

In brief, the data analysis brought to light various strategies used by physicians to manage the psychological stress associated with being a messenger of bad news. They tried 
to focus on the positive aspects of bad news events, reasoned that medical science had no solutions for all problems, maintained emotional distance from patients, engaged in nonclinical activities, and kept their professional and personal lives separate. They also emphasized drawing on resources such as spirituality and support from persons in their intimate and professional circles.

\section{Bad news bearers' bonuses}

Participants emphasized that delivering bad news was never an easy or a pleasant task, but paradoxically these patient care situations brought them blessings in disguise. Many of them perceived positive growth in personal, professional, and social aspects of their lives due to exposure to bad news consultations. Although breaking bad news was emotionally draining, participants believed that it helped them to empathize with patients and their families and thereby to become better care providers. A female obstetrician summed it up very well:

"Positively means, I gain the experience and I see that it adds to my experience. The mistakes that I have done previously they won't be repeated. That's how it has the positive effect."

Participants talked about increased awareness about the frailty of life and that no one is immune from disease and death. A surgical oncology specialist spoke about his ability to see life differently:

"I think it is positive for us. I don't think [that] working with the cancer patients has a negative impact on me and my life. It has always helped me to see life in a better light."

They suggested that their experience of breaking bad news has helped them to have a more balanced perspective on their own lives and life in general. Some quotes that illustrate this are: "[I] feel a little bit more relaxed in life." "[I am] generally more forgiving and [more of a] nonviolent person." One physician said he had learned to refrain from "giving importance to petty issues" and instead concentrates "on issues that matter to many [people]".

Being a bearer of the bad news positively affected spirituality and helped physicians recognize the spiritual dimension of patient care. A pediatrician shared the following when discussing the positive aspects of bad news interactions:

\footnotetext{
"Over the years I have realized--in the beginning years of my career, I was thinking that what I do is ultimate--no, I have realized that we are nothing. We are totally a non-entity. Nohting, nothing. Even a small grass can be changed, its position changed without His will. So why bother about all these? Do your best; tell the facts; sit back and leave it to God. If faith is there, it may do wonders. Patients are also able to accept it. That's one thing, I really learned over the years. I think that there should be a spiritual dimension to the entire healing process, which we have neglected."
}

As for the positive effects on their professional life, participants reported an increased capacity to provide better care by avoiding communicational pitfalls. Some of them said that bad news situations taught them to be passionate for their patients and to empathize with them by personalizing their pain, as expressed by a medical oncologist:

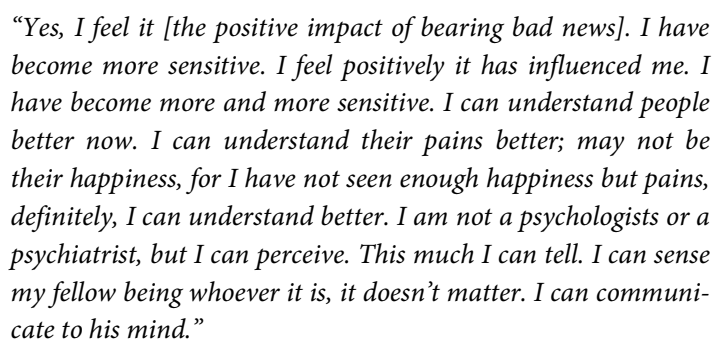

Analysis of the data revealed that some clinicians who deal with bad news gain the ability to accept failure and defeat in medical care. In this regard a male oncologist said:

"I think it [bad news consultation] affects us for the better.... We deal with certain issues which are very difficult and we lose always. May be, most of the time we lose the battle against the disease. So, we have learnt to take defeat in life, in that sense."

Another female gynecologist explained:

"Positively means I gain the experience and I see that it adds to my experience. The mistakes that I have done previously they won't be repeated. That's how it has the positive effect."

Some of the participants spoke about the impact of bad news encounters on their spiritual and existential beliefs. A clinician in the department of pain and palliative medicine said:

"Yes, whenever I see so many young patients dying, it will make
you to go more of spiritual. You realize that anything can hap-
pen to anybody. You are not immune from it. In that way, it
makes me to take everything, whatever good things or bad
things in life. I am not very much elated or very much depressed
with any of the things, I would try to have equilibrium. So, in
that way, I would say, it does not adversely affect my life."

In summary, the physicians in this study, who had all discovered and delivered bad news to patients and families, experienced various emotions and levels of psychological distress that persisted from a few hours to many days and weeks. All of them perceived adverse effects on their personality and professional life but some of them also described bad news situations as blessings in disguise for the growth opportunities they provided. All of them emphasized the importance of learning coping strategies and having access to social supports to manage their distress and thereby to better support the recipients of bad news.

\section{Discussion}

This study is significant because for the first time the burdens and behaviours of the bearers of bad news in India are examined. Previous studies focused primarily on physicians' ethical perspectives on truth disclosure and made only general comments on the challenges faced by them. The current study emphasizes that being a messenger of bad 
news is not like couriering information in a sealed envelope, carefree of its contents and consequences to the recipients. Instead, bad news for patients and families is identified as bad news for the physicians too, and it affects various aspects of their lives.

Several insights gained through research done across the globe are substantiated through this study. For example, the perceptions of our participants that bad news interactions are always challenging and that more years of clinical practice do not necessarily make truth telling easier or the quality of such consultations better, is in line with findings reported by Fallowfield and colleagues. ${ }^{32}$ The current study suggests that several factors related to patients, families, clinicians, disease, and clinical relationships impinge on the process of truth disclosure and generate different levels of stress. This corresponds with the findings of Ptacek $^{33}$ who analyzed 94 unique responses of 32 physicians who described the issues that made truth disclosure a stressful experience for them and grouped these issues in relation to the physician, patient, institution, type of illness, and patient-physician relationship.

The extant literature identifies the situations that make bad news disclosure more stressful for clinicians. For example, unfamiliarity between patients and physicians, ${ }^{10}$ having little or no exposure to bad news consultations, ${ }^{11}$ lack of special interactional skills, ${ }^{34}$ treatment failure or toxic outcomes, and medical errors ${ }^{20,33}$ are some of the issues that make truth disclosure more stressful for clinicians. Many of these issues are captured through this study, but in addition, it highlights the socioeconomic condition of patients, specifically the lack of access to treatment, as a context that generates intense helplessness and a sense of defeat among clinicians. Often we associate the burdens of breaking bad news with inadequacies of individuals involved in such interactions. The systemic source of burden has remained largely invisible in the global literature on truth disclosure. We were surprised to learn that most of our participants considered the decision to withdraw effective or promising treatments from patients who could not pay for them as the most disturbing personal and professional defeat. Systemic sources of distress may be more pronounced in countries such as India that do not have publicly-funded universal health care, where timely and effective health care is a privilege rather a right.

This study has brought to light several psychological processes by which physicians in India cope with the stress associated with bad news consultations. An experimental study by Bernard, et al. ${ }^{35}$ with 56 clinicians engaged in clinical interaction with simulated patients revealed that the stress associated with bad news disclosure induced clinicians to use a higher number and a greater variety of defense mechanisms than those in the control group. Further, these researchers listed and assessed 30 defenses with the help of the Defense Mechanism Rating Scale (DMRS-C) and noted that displacement, intellectualization, and rationalization are the most frequently used defenses. Displacement was evident in the abrupt shifting of conversation in the context of highly emotional content, intellectualization in the use of excessive medical or technical explanations, and rationalization involved a refusal to attend to the emotional distress expressed by patients. Strategies used by clinicians in India such as seeing the positive side of a bad news event, recognizing the limitedness of medical science, and engaging in activities that lower their distress may be beneficial to health care providers in any society or setting. However, defenses such as detachment, compartmentalization, and avoiding empathic attachment should be examined and evaluated further because, as Farve $^{36}$ noted, defense mechanisms protect clinicians from painful emotions but might prevent them from recognizing patients' suffering. Similarly, reflecting on his personal experiences, Berry ${ }^{37}$ suggested that physicians often try to overcome a sense of helplessness by separating themselves from patients' suffering in the face of therapeutic failure, which initiates in them the insidious process of dehumanization and atrophy of affect.

Insights about growth at the personal and professional level underscore the capacity and effort of humans to make meaning in the face of the challenges posed by bad news events. The knowledge that at least some clinicians are able to integrate the burden of being the messenger of bad news as an inevitable part of their lives provides impetus for further research in India and elsewhere to examine the personal and societal resources required to generate perceptions of positive growth amidst bad news. Previous studies have highlighted the benefits of support structures such as multidisciplinary palliative care teams to lower the stress of working in acute care units ${ }^{38}$ and to increase the capacity of health care professionals to handle the emotions of failure and sorrow, which might otherwise result in psychological morbidity and burnout. ${ }^{1,39,40}$

We have initiated a research program that focuses on the messengers of bad news by exploring the experiences of 27 physicians in India. Some of these findings may be useful to health care professionals belonging to different disciplines and carrying out various patient care duties; however, more studies are needed to understand the unique perspectives of nurses, social workers, psychologists, spiritual workers, and health administrators. A qualitative study with 27 physicians working in four hospitals in two cities barely represents the emergency and critical care services and their impact of truth disclosure across India, so it would be good to conduct studies with larger, representative samples. The nuances of bad news, the frequency of such interactions, and the consequences of being the messenger of bad news are likely to differ in societies having a higher incidence of life-limiting diseases, higher mortality rates, greater inequities in health care access, and resource-starved medical education. This topic should therefore be examined in the 
context of many other developing countries and clinical settings.

\section{Conclusion}

This study held a mirror to the psychosocial burdens of physicians engaged in truth telling in India and it highlighted the need to make hospitals safe and healthy work settings for physicians, not merely centres meant to cure patients. The findings suggest that paying attention to the psychosocial burdens of the messengers of bad news and availing them of the necessary resources through better training helps them to cope with this clinical responsibility, which ultimately serves the best interests of patients and families.

The study has significance for medical education in India and internationally; in particular, it provides insights to improve clinical communication training. When speaking about truth or bad news disclosure as a special clinical skill, we think about the efficient ways of transmitting unfavorable information to patients and families and helping them to tolerate the distress associated with such transactions. We seldom think about the impacts of such consultations on clinicians. Clinical communication training should focus equally on the psychosocial needs of physicians who discover and deliver bad news because the ability to manage their own stress is an integral aspect of their communicative competence. Clinicians are a prominent resource and first point of support to patients and families. The physicians who have problems managing their own psychosocial stressors are less likely to communicate with patients and their families effectively and with empathy. Hence, Ptacek and colleagues ${ }^{15}$ suggested that medical education and ongoing training programs should include guidance on cognitive and behavioural coping strategies. Previous studies that examined the truth telling attitudes of clinicians and medical students in India have noted the dissatisfaction of their participants with their training for such interactions ${ }^{23-25}$ and ineffective training initiatives. ${ }^{41}$ The absence of research on the psychosocial impacts of bad news interactions on health care professionals who are the messengers of bad news might have diminished the effectiveness of existing training programs.

Medical education should place as much emphasis on skills related to assessing and attending to the psychosocial impacts of delivering bad news on physicians' lives as teaching them the procedures to convey such information. Clinical skill training has been found to be useful in teaching clinicians mature defenses. ${ }^{35}$ This study underscores the need for physicians to learn self-care skills to mitigate the effects of the psychological distress associated with delivering bad news on their personal, social, and professional lives. Further, we found that it was not only the severity and type of disease, that is, the medical truth that makes clinical interactions burdensome for physicians but the socioeconomic status of the patient as well. Medical education should not be restricted to teaching interactional or coping skills, but also include ways to advocate for support services for physicians, and policies and programs to ensure equitable access to health care for all citizens. Clinical skills training arranged as part of both regular and ongoing medical education should help physicians recognize the systemic sources of distress they experience when dealing with clinical bad news. This is important because even the higher order defences or best of psychological mechanisms may not help clinicians to cope with the distress that has its basis in an inequitable, unresponsive, fragmented and suboptimal health care system.

\section{Conflict of Interest}

The authors declare that they have no conflict of interest.

\section{References}

1. Fallowfield L, Jenkins V. Communicating sad, bad, and difficult news in medicine. Lancet. 2004;363:312-9.

2. Baile WF, Lenzi R, Parker PA, Buckman R, Cohen L. Oncologists' attitudes toward and practices in giving bad news: an exploratory study. J Clin Oncol. 2002;20(8):2189-96.

3. Butow PN, Kazemi JN, Beeney LJ, Griffin AM, Dunn SM, Tattersall MH. When the diagnosis is cancer: patient communication experiences and preferences. Cancer. 1996;77(12):2630-37.

4. Brown JB, Stewart J, McWilliams C. Using the patient-centered method to achieve excellence in care for women with breast cancer. Patient Educ Couns. 1999;38:121-9.

5. Baile WF, Buckman R, Lenzi R, Glober G, Beale EA, Kudekla AP. SPIKES - a six-step protocol for delivering bad news: application to the patient with cancer. Oncologist. 2000;5(4):302-11.

6.Thompson TL. The nature and language of explanations. In: Whaley B, editor. Explaining Illness. 2000; Mahwah, NJ: Lawrence Erlbaum Associates; 2000.

7. Lamont EB, Christakis N. The complexities in prognostication in advanced cancer: "to help them live their lives the way they want to". JAMA. 2003;290(1):98-104.

8. Buckman R. How to break bad news: a guide for health care professionals. Toronto, ON: University of Toronto Press; 1992.

9. Lobb EA, Butow PN, Kenny DT, Tattersall MH. Communicating prognosis in early breast cancer: do women understand the language used? Med J Aust. 1999;171(6):290-4

10. Hulsman RL, Pranger S, Koot S, Fabriek M, Karemaker JM, Smets EMA. How stressful is doctor-patient communication? Physiological and psychological stress of medical students in simulated history taking and bad-news consultations. Int J Psychophysiol.2010;77:26-34.

11. Brown R, Dunn S, Byrnes K, Morris R, Heinrich P, Shaw J. Doctors' stress responses and poor communication performance in simulated badnews consultations. Acad Med. 2009; 84:1595-1602.

12. Cohen L, Baile WF, Henninger E, Agarwal, SK, Kudelka AP, Lenzi R, et al. Physiological and psychological effects of delivering medical news using a simulated physician-patient scenario. J Behav Med. 2003;26:459-71.

13. Friedrichsen M, Milberg A. Concerns about losing control when breaking bad news to terminally ill patients with cancer: physicians' perspective. J Palliat Med. 2006;9(3):673-82.

14. Dosanjh S, Barnes J, Bhandari M. Barriers to breaking bad news among medical and surgical residents. Med Educ. 2001;35:197-205.

15. Ptacek JT, Fries EA, Eberhardt TL, Ptacek JJ. Breaking bad news to patients: physicians' perceptions of the process. Support Care Cancer. 1999;7:113-20.

16. Iserson KV. The gravest words: sudden-death notifications and emergency care. Ann Emerg Med. 2000;36:75-77.

17. Kalber B. Breaking bad news- whose responsibility is it? Eur J Cancer Care. 2009;18(4):330.

18. Cooke MW, Cooke HM, Glucksman EE. Management of sudden bereavement in the accident and emergency department. BMJ.1993;304: 1207-09. 
19. Fallowfield L. Can we improve the personal and professional fulfilment of doctors in cancer medicine? Br J Cancer.1995;71:1135-36.

20. Ramirez AJ, Graham J, Richards MA, Cull A, Gregory WM, Leaning MS, Snashall DC, Timothy AR. Burnout and psychiatric disorder among cancer clinicians. Br J Cancer.1995;71:1263-69.

21. Lipton H. Mental health needs for providers of emergency services for children: a report of a consensus panel. Prehosp Emerg Care.2002;6:15-21.

22. World Health Organization. Mortality and disease burdens - India (Data file-2009). [Cited 18 December 2012]; Available from: http://www.who. int/countries/ind/en/.

23. Bharadwaj P, Vidyasagar MS, Kakria A, Alam TU. Survey of palliative care concepts among medical students in India. J Palliat Med. 2007;10(3) :651-3.

24. Supe A. Interns' perspectives about communicating bad news to patients: a qualitative study. 2011 [Cited 18 December 2012]; Available from: http://www.educationforhealth.net/.

25. Kumar M, Goyal S, Singh K, Pandit S, Sharma DN, Verma, AK, et al. Breaking bad news issues: a survey among radiation oncologists. Indian J Palliat Care. 2009;5(1):61-6.

26. Creswell JW. Qualitative inquiry and research design: choosing among five approaches. New Delhi: Sage Publications; 2007.

27. Glaser B, Strauss A. The discovery of grounded theory: strategies for qualitative research. New York: Aldine; 1967.

28. Charmaz, K. Constructing grounded theory: a practical guide through qualitative analysis. London, UK: Sage Publications; 2006.

29. Healy M, Perry C. Comprehensive criteria to judge validity and reliability of qualitative research within the realism paradigm. Qualitative Market Research Journal. 2000;3(3):118-26.

30. Glaser B. Basics of grounded theory analysis. Mill Valley, CA: Sociology Press; 1991.
31. Glaser B. Theoretical sensitivity. Mill Valley, CA: Sociology Press; 1978. 32. Fallowfield L, Jenkins V, Farewell V, Saul J, Duffy A, Eves R. Efficacy of cancer research in $\mathrm{UK}$ and communication skills training model for oncologists: a randomized controlled trial. Lancet. 2002;359:650-6.

33. Ptacek JT, MacIntosh EG. Physician challenges in communicating bad news. J Behav Med. 2009;32:380-87.

34. Gillotti C, Thompson T, McNeilis K. Communicative competence in the delivery of bad news. Soc Sci Med. 2002; 54:1011-23.

35. Bernard M, de Roten Y, Desplant JN, Stiefel F. Communication skills training and clinicians' defenses in oncology: an exploratory, controlled study. Psycho-Oncology.2010; 19:209-15.

36. Favre, N. Despland JN, de Roten Y, Drapeau M. Bernard M, Stifiel F. Psychodynamic aspects of communication skills training: a pilot study. Support Care Cancer.2007;15:333-37.

37. Berry PA. The absence of sadness: darker reflections on the doctor patient relationship. J Med Ethics. 2007;33:266-8

38. Pierce B, Dougherty E, Panzarella T, Le LW, Rodin G, Zimmermann C. Staff stress, work satisfaction, and death attitudes on an oncology palliative care unit, and on a medical and radiation oncology inpatient unit. J Palliat Care. 2007;23(1):32-9.

39. Loge JH, Kaasa S, Ekeberg O, Falkum E, Hytten K. Attitudes towards informing the cancer patients: a survey of Norwegian physicians. Eur J Cancer.1996;32(8):1344-48.

40. Ramirez AJ, Graham J, Richards MA, Cull A, Gregory WM. Mental health of hospital consultants: the effects of stress and satisfaction at work. Lancet.1996;347:724-8.

41. Velayudhan Y, Ollapally M, Upadhyaya V, Nair S, Aldo M. Introduction of palliative care into undergraduate medical and nursing education in India: a critical evaluation. Indian J Palliat Care.2004;10(2):55-60. 